\title{
LA GUERRA PÉRDIDA DEL INDIO LORENZO, DE RAFAEL BAENA: ¿NOVELA INDIGENISTA O CON INDIOS?
}

\section{THE RAFAEL BAENA LA GUERRA PERDIDA DEL INDIO LORENZO: INDIGENOUS NOVEL OR WITH INDIANS?}

\author{
Juan Carlos Orrego Arismendi \\ Universidad de Antioquia, Colombia. \\ juan.orrego@udea.edu.co
}

\begin{abstract}
Resumen:
Este artículo analiza la manera en que se da cuenta de lo indígena en La guerra perdida del indio Lorenzo (2015), la última novela publicada en vida por el escritor colombiano Rafael Baena (1956-2015). El pretendido carácter indigenista de la obra, anunciado ya desde el título epónimo, no se correspondería con el protagonismo apenas relativo del personaje de Victoriano Lorenzo ni con otros elementos que problematizan la reivindicación de una cuestión indígena particular.
\end{abstract}

Palabras clave: Rafael Baena, La guerra perdida del indio Lorenzo, novela colombiana, indios en la literatura, indigenismo literario.

\begin{abstract}
:
This article analyzes the manner we become aware of the indigenous theme in La guerra perdida del indio Lorenzo (2015), the last novel published by the Colombian author, Rafael Baena (1956-2105) during his lifetime. The presumptive indigenist character of the work, already announced from the eponymic title, would not correspond with the hardly reletive protagonism of the Victoriano Lorenzo's character nor with other elements that problematize the vindication of a particular indigenous issue.
\end{abstract}

Keywords: Rafael Baena, La guerra perdida del indio Lorenzo, Colombian novel, Indians in literature, Literary indigenism.

Recibido: 16 de octubre de 2018

Aceptado: 06 de mayo de 2019 


\section{Introducción: novelas colombianas de tema indígena en el tercer lustro del siglo XXI}

No puede negarse la singularidad de la hornada de novelas de tema indígena publicadas en Colombia en el tercer lustro del siglo XXI. Ello, dicho sea de paso, puede tomarse como prueba indiscutible de que esa modalidad literaria no solo mantuvo vigencia después del apogeo del neoindigenismo en los mismos días del Realismo Mágico, sino que no ha estado ausente en ninguna época del registro literario en el país. ${ }^{1}$ Tal singularidad radica sobre todo en la representatividad o el reconocimiento alcanzado por algunos de los autores o en la originalidad que se adivina en las propuestas, como acaso logra mostrarlo una breve ojeada sobre el panorama.

En La serpiente sin ojos (2012), William Ospina retomó-como en su momento lo hicieron autores latinoamericanos canónicos como Arturo Uslar Pietri, Miguel Otero Silva y Abel Posse - la aventura conquistadora de Lope de Aguirre en la selva y el litoral venezolanos. Menos visible en los círculos comerciales de la literatura colombiana, Selnich Vivas Hurtado dio a luz Finales para Aluna (2013), en la que las tesis del neoindigenismo se extreman al punto de presentarse un argumento en que, en ausencia de personajes indígenas, se reivindica con firmeza - y con legítimo asidero etnográfico - la cosmovisión del pueblo mınłka, y ello sin importar que la historia narrada tenga lugar en Alemania. Ese mismo año se publicó una novela de tema muisca, Príncipe de Chía: Enfrentamiento de dos

\footnotetext{
${ }^{1}$ En otros trabajos ya hemos reconstruido la reflexión crítica latinoamericana sobre las modalidades o periodos de la narrativa de tema indígena, y preferimos no hacerlo una vez más aquí. Quizá solo convenga saber, a propósito de nuestra alusión, que en su artículo "Tercer avatar del indigenismo literario" (2004), Julio Rodríguez-Luis cree ver en el neoindigenismo (corriente caracterizada sobre todo por la inclusión de la cosmovisión y la mitología amerindias en el registro literario) un capítulo especial del indigenismo, el cual se concentraría, a su vez, en un abordaje mucho más externo que pretende mostrar y denunciar las condiciones críticas de vida de los diversos pueblos nativos del continente. En La narrativa indigenista peruana (1994), Tomás G. Escajadillo llama "indigenismo ortodoxo" a la corriente que aún no ha incorporado elementos de la cosmovisión —o que por lo menos no lo ha hecho a fondo-, y que al situarse con "proximidad" frente a la vida indígena - con el consecuente relegamiento de cualquier perspectiva romántica- puede invocar condiciones objetivas para plasmar un auténtico "sentimiento de reivindicación social" (Escajadillo 41-43). Esta noción de la reivindicación social, entendida como un elemento definitorio - aunque no único - del indigenismo, también había sido invocada por Luis Alberto Sánchez en Proceso y contenido de la novela hispanoamericana (1953), quien bebe de los ensayos de Manuel González Prada y José Carlos Mariáteguisobre la "cuestión del indio", publicados en las primeras décadas del siglo XX, y en los que se señala de modo radical la necesidad de iniciar la restitución social del indígena peruano con la devolución de las tierras ancestrales usurpadas desde la Conquista (González Prada 177-190; Mariátegui 35-55).
} 
mundos, de Omar Adolfo Arango, obra que alcanzó el segundo lugar en el International Latino Boook Awards de 2014. Por su parte, Pablo Montoya alcanzó el Premio Rómulo Gallegos con una novela que, como Tríptico de la infamia (2014), se interesa por la vida de los timucuas de la Florida en el siglo XVI. Finalmente, en 2015 se conoció el último libro publicado en vida por Rafael Baena - uno de los novelistas históricos más leídos en la última década en Colombia-: La guerra perdida del indio Lorenzo, trabajo que llama la atención no solo por ocuparse del episodio casi olvidado —al menos desde la óptica colombiana - de la secesión de Panamá, sino por apelar a la historia de un levantamiento indígena, presumiblemente a tono con las expectativas del indigenismo ortodoxo latinoamericano de la primera mitad del siglo $\mathrm{XX} .^{2}$

Nuestro interés se concentra en la última de las novelas del inventario, habida cuenta, precisamente, de esa presunta ligazón con el indigenismo, misma que a primera vista estaría materializada en la explícita referencia del título. En esto, apelamos a las reflexiones de Álvaro Pineda Botero sobre la función del título en la novela. Este escritor y crítico colombiano se remite a Ferdinand de Saussure para establecer que al título le corresponden los atributos del signo linguiístico, y por ello su valor estaría referido a un número indefinido de relaciones asociativas, esto es, a todo aquello que, no siendo explícito en el título, hace presencia por medio de él; escribe el autor: "Las palabras no sólo tienen un significado sino que evocan el significado de otras relacionadas con ellas por afinidad fonética y semántica, por derivación o exclusión. Además, las palabras ganan significado como si tuviesen memoria" (Pineda Botero 52). Enseguida, acercándose a Roland Barthes, establece que el título está conformado por "todo aquello que la historia, el uso, el arte, la cultura han puesto en él”, y que por fuerza evoca unos escenarios (53). Así pues, el título La guerra perdida del indio Lorenzo no podría dejar de manifestar algún tipo de relación con obras históricas y literarias de cuño indigenista escritas en Colombia — sobra decir que ese marco político-administrativo podría ampliarse_-, y en las que la expectativa por la reivindicación del indio, su lucha y su vencimiento se expresan con nitidez. Un mínimo

\footnotetext{
${ }^{2}$ El inventario de novelas de tema indígena aparecidas en Colombia en los últimos años no termina ahí: en 2014 se publicó Santa María del Diablo, de Gustavo Arango, novela cuyo argumento echa raíces en la conquista de la zona del Darién —en el golfo de Urabá- durante el siglo XVI. De 2015 es Moxa: El hijo del Sol, de Ernesto Zarza González, otra novela histórica de tema muisca. Asimismo, en los últimos díasde 2016 apareció en las librerías colombianas Palabrero, novela de Philip Potdevin interesada por diversas vicisitudes contemporáneas de la etnia wayúu en su compleja relación con el Estado colombiano.
} 
corpus de obras canónicas adscritas a esa tradición podría estar compuesto por el ensayo "La melancolía de la raza indígena" (1929), de Armando Solano; la monografía El indio en lucha por la tierra (1944), del antropólogo colombo-ucraniano Juan Friede, y la novela La tierra es del indio (1955), de Jaime Buitrago, sin contar con que el sentido epónimo del título de la novela de Baena — por lo demás característico en la literatura indigenista latinoamericana - la ligaría con José Tombé (1942), de Diego Castrillón Arboleda, ${ }^{3}$ novela que es trasunto de las correrías armadas de Manuel Quintín Lame y que constituye el clímax de la novela indigenista colombiana.

A la luz de lo anterior surge la inquietud que suscita este trabajo: ¿Con La guerra perdida del indio Lorenzo ha resurgido, en Colombia, un indigenismo cuya edad dorada habría tenido lugar más de medio siglo atrás? Es por lo menos llamativo que un proyecto semejante parezca cobrar bríos en una época que, como la actual, ha privilegiado una literatura de tema indígena en que el nativo aparece como un protagonista - entre otrosde diversos episodios históricos multiétnicos, aunque esta vez vestido sin los disfraces aparatosos del romanticismo y, más bien, construido verosímilmente con apoyo en la profusa documentación histórica que los académicos contemporáneos han puesto al servicio de la creación literaria. ${ }^{4}$ Conviene revisar con detenimiento si, más allá del presunto rótulo indigenista, se despliega en efecto una novela que pueda ser clasificada de esa manera.

\section{Elementos indígenas en La guerra perdida del indio Lorenzo}

La guerra perdida del indio Lorenzo se interesa por los hechos bélicos que tuvieron lugar en Panamá en la coyuntura que llevó a su separación de Colombia; en concreto, los que acaecieron entre los preparativos de la Batalla del Puente de Calidonia y la firma del armisticio en el vapor Wisconsin o, más exactamente, hasta el fusilamiento del general indígena Victoriano Lorenzo en los días que siguieron al pacto entre conservadores y

\footnotetext{
${ }^{3}$ A propósito de la representatividad de José Tombé véase el corpus de novelas hispanoamericanas de tema indígena que Gerald Wade y William Archer comentan en su artículo "The Indianista Novel since 1889" (1950).

${ }^{4}$ Se trata de una coyuntura profusamente analizada — al menos en lo que respecta al periodo 1979-1992 — por Seymour Menton en La Nueva Novela Histórica de la América Latina 1979-1992 (1993), y que en años más recientes ha sido actualizada, en cierto sentido, por un artículo de Carolina Pizarro Cortés: “¿Debería aceptar yo sin más, las paparruchas y embustes de vuestros cronistas?' (Las nuevas crónicas de Indias como reescrituras del Descubrimiento y la Conquista)" (2010).
} 
liberales; un periodo histórico que se extiende entre junio de 1900 y mayo de 1903, y del que la narración solo revela indicios parciales. La novela no es otra cosa que el texto de una larga carta - fechada en diciembre de 1913 - que Vicente Orduz, mayor retirado del ejército liberal, le escribe a su sobrino Saúl Cantor para despejar sus inquietudes a propósito de sus experiencias panameñas y, particularmente, sobre su relación con el general indio. Orduz había conocido a Lorenzo con motivo de un desembarco de armamento efectuado en las playas de Chame poco antes de los hechos de Calidonia, y tuvo una relación de camaradería con él a lo largo de las vicisitudes guerreras que siguieron, en medio de la irregular sucesión de triunfos, reveses y cambios de mando y de estrategia que caracterizaron la guerra partidista en el istmo en los primeros años del siglo XX.

Vicente Orduz y su familia ya habían sido los personajes de otra novela histórica de Rafael Baena: La bala vendida (2011), en la que se relatan lavida y aventuras de los hermanos Orduz por los días en que se libraron las batallas de Peralonso y Palonegro, hitos sangrientos de la Guerra de los Mil Días. De hecho, el mismo Saúl Cantor surge como personaje en esas páginas, hijo de un soldado liberal y Débora Orduz, hermana mayor de Vicente y ama de la hacienda Saia, situada en algún rincón del Departamento de Santander. Sin embargo, esas circunstancias familiares poco pesan en la nueva novela o por lo menos no al punto de hacerla dependiente del antecedente: quizá solo importe saber que el sobrino nació poco antes de la guerra que selló la separación de Panamá y que su tía Micaela —a quien, ahora, Vicente encuentra en el istmo - había sido flagelada y envilecida por el ejército conservador poco tiempo después del desmadre liberal en Palonegro; porque Vicente Orduz, en tanto autor de la carta, se encarga de contar brevemente cómo se las ingenió él mismo para pasar de Santander a Panamá. Lo cierto, sin embargo, es que su historia personal importa muy poco más allá de eso, como no sea a propósito de sus aventuras corrientes como militar en el istmo, sus fantasías amorosas con la hija de su anfitrión en Colón y su fugaz encuentro, en la casa de este último, con su hermana Micaela, sobreviviente del referido escarnio. Todo lo demás son los hechos bélicos que otros personajes protagonizan en Panamá, y frente a los cuales Orduz presta su concurso de testigo y cronista, y aun al precio de convertirse en poco más que un actor de reparto.

Uno de los actores de la guerra es el indio Lorenzo, quien, del mismo modo que el narrador, cumple un papel de relativa importancia en un escenario en que también 
descuellan figuras como Belisario Porras, Emiliano Herrera, Carlos Albán, Gabriel Vargas Santos y otros generales afiliados a los dos bandos en contienda. Orduz, al mando de un batallón de caballería que combatía junto con la gente de Lorenzo con la misma frecuencia con que debía alejarse para cumplir con diversas misiones encomendadas por los cabecillas liberales, aprovecha las diversas apariciones del indio en el foco de la narración para establecer sus rasgos característicos. Con ocasión de un operativo en Chame, el mayor ofrece a su sobrino una instantánea de la apariencia física y el estatus que el "cholo" como en repetidas ocasiones llama a su antiguo compañero de lucha- ocupaba entre su gente: "Los estibadores parecían hacer caso omiso de la presencia a todas luces puntillosa de Herrera, pero nada más llegar Porras al lugar, uno de ellos, un indio cetrino y bajito de rostro afable que evidentemente era el líder, caminó hacia él y lo saludó abrazándolo con efusión" (Baena, La guerra 31). Al avanzar la epístola se informa, incluso, de un rasgo en extremo particular de la anatomía de Lorenzo, como puede serlo el que, en sus pies, el dedo gordo estuviera notoriamente separado de los demás, "señal de estar habituados a bregar en lodazales y trepar a los árboles para otear presas de caza o coger frutas”. Con ello, el narrador sitúa al indio en lo "característicamente campesino" (70).

Orduz también revela otras noticias -igualmente escuetas - sobre la formación de Lorenzo y los motivos que lo llevaron a la lucha armada, de modo que logra saberse que procedía de la zona montañosa de Coclé; que, de niño, había sido educado por jesuitas, y que ya adulto se había levantado en armas para proteger a su pueblo de los abusos tributarios del gobierno local. Este aspecto de la vida de Lorenzo se presenta significativamente enmarcado en una larga tradición colonial:

Desde siempre, el gobierno de los blancos les cobraba impuestos por sembrar, por vender la cosecha, por la venta de un semoviente y por el comercio de la sal. No eran imposiciones de nuevo cuño sino que obedecían a toda una cultura cuyos orígenes se remontaban a los tiempos de los reyes Carlos y Felipe con el propósito de sojuzgar a los indígenas. El método de cobrarles manu militari se mantenía inalterable desde entonces y eran incontables las humillaciones que sufrían de parte de los soldados convertidos en recaudadores fiscales. (37-38) 
De hecho, la segunda alusión del narrador al yugo tributario al que estaban uncidos los indios de Coclé le permite vincular un elemento significativo de la historia y la cultura locales, de cara a la apremiante reivindicación del pueblo sometido: la figura del cacique Urracá, quien en el siglo XVI enfrentó los asedios de Gaspar de Espinosa, subordinado del implacable Pedrarias Dávila. Orduz impone a su sobrino del profundo interés que ese líder nativo suscitaba en Lorenzo:

Admiraba como un prócer al cacique Urracá, que presentó resistencia a los conquistadores y convirtió las selvas del istmo en un infierno para los hombres de la cruz y de la espada [...]. Gozaba mucho el capitán al narrarme la forma en que las armaduras españolas empezaron a ser carcomidas por el orín, el acero toledano de las espadas a perder lustre, la pólvora de los arcabuces a convertirse en naco de azufre y los caballos a romperse las manos en los caminos de montaña mientras las flechas y lanzas de los indios los convertían en alfileteros. (65-66)

La sustancia política de esa evocación se torna especialmente densa en el pasaje de la carta referido al ascenso de Lorenzo como general. En efecto, allí logra verse al líder de Coclé "con el puño en alto" mientras, al dar la cara a sus seguidores, replica una consigna genérica que la "tradición” atribuye a Urracá: "Más vale morir peleando en la guerra que vivir la vida con fatiga, dolores, amarguras y sobresaltos"; y todo ello desemboca en un reclamo por el despojo de la tierra ancestral por cuenta de los gobiernos y los hacendados (72-73). Esto hace que Lorenzo, cuya graduación como general no se ha efectuado del modo más ortodoxo — se trató, en esencia, de una aclamación popular — resulte, más que los militares blancos, preñado de un "poder simbólico” (186).

Como parecerá obvio, la complacencia ante la figura de Lorenzo - la tácita celebración de su evolución política - pertenece particularmente a Orduz en tanto autor de una carta pedida por su sobrino, con quien comparte un mismo fervor social. A otra valoración de las cosas indias se suscribían los otros dirigentes militares y los políticos de élite, por no decir que los demás blancos y buena parte del pueblo panameño. Al general liberal Manuel Antonio Noriega, por ejemplo, le era enojoso aceptar que sus copartidarios fueran — como la gente de Lorenzo- “individuos de inferior condición” (92). Los conservadores, a su vez, entendían su causa como "una cruzada del progreso contra el 
salvajismo" y, en consecuencia, destacaban como una de sus consignas la de "Cholo visto, cholo muerto" (146); un propósito que llegó a materializarse con especial crudeza cuando, con motivo del combate de Aguadulce, seis cholos liberales fueron capturados por las fuerzas gobiernistas y masacrados sin miramiento alguno porque, a fin de cuentas, "no alcanzaban la condición de humanos" (155). Con todo, parte de esa expectativa habría tenido algún asidero en hechos objetivos; por lo menos eso es lo que sugiere la conducta del cholo Fidel Murillo, quien se precipitó sobre el cuerpo del coronel conservador Pedro Sotomayor - abatido en el sitio de La Negrita - y macheteó su cabeza con inútil barbarie: "la barbarie más abyecta e inimaginable" a juicio de los propios liberales (101).

El cierre de la carta de Orduz ofrece las noticias de los últimos días del general Victoriano Lorenzo, ejecutado tanto por su fuero rutilante de caudillo nativo $-\mathrm{y}$ en ese sentido amenaza del acuerdo politiquero firmado en el Wisconsin- como por su condición étnica — sinónimo de desclasamiento social y equívoca humanidad—. Las noticias sobre la postración moral de Lorenzo, así como los hechos de su prisión y fusilamiento - llevado a cabo el 15 de mayo de 1903 en Ciudad de Panamá-, sirven de marco a una escéptica reflexión del narrador sobre el fatal cumplimiento de una historia elitista, edificada sobre un statu quo ajeno a las aspiraciones de los pueblos nativos o subalternos: "el tema menos sustancial para los firmantes del armisticio era prestar atención a las expectativas de los cholos, o de los negros, o de cualquiera que no integrase el cerrado anillo de intereses políticos y económicos que pugnaban por imponerse en Panamá y en últimas en toda Colombia" (215). Desde esa óptica, la guerra perdida de Lorenzo resulta tener un valor representativo incluso mayor que el que corresponde a la resistencia indígena de Urracá en el siglo XVI.

\section{Problemas de la reivindicación indigenista en la novela de Rafael Baena}

Una lectura apenas somera de La guerra perdida del indio Lorenzo deja ver la brecha que separa la promesa del título — un protagonismo rotundo del personaje, forjado en las dificultades de su carrera militar - con el volumen de las apariciones objetivas de Victoriano Lorenzo en la novela. Aunque la del indio de Coclé es, sin duda, una de las figuras más visibles en la narración, su protagonismo propiamente dicho apenas puede ser 
relativo, toda vez que sus acciones no alcanzan a ser más relevantes que las de Albán, Herrera, Porras y otros militares comprometidos en la guerra panameña. Por lo demás, en muchos pasajes Lorenzo desaparece del foco de la novela; por ejemplo, no está incluido en la larga relación de los hechos acaecidos cuando Orduz se pone bajo las órdenes de Ramón Buendía, encargado de la defensa del sitio de Bocas del Toro; asimismo, no hay referencias al indio en la crónica de la contienda naval en que pierde la vida el general Albán. En otros episodios, la participación de Lorenzo se materializa en alusiones escuetas a los movimientos de sus hombres durante los enfrentamientos, tal como lo ilustra un ejemplo entre muchos: "Lorenzo y Porras guiaron a sus hombres para atravesar un estero que se oponía entre su posición y El Vigía" (156). Por lo demás, no es casual en ese extracto la posición paralela — en equilibrio - del general indio y el general blanco.

La novela latinoamericana de tema indígena ha mostrado, desde su presunta inauguración con la anónima Jicoténcal (1826), una marcada tendencia hacia el trazo épico; hacia la concentración narrativa en el accionar de un héroe definido que, las más de las veces, es un indio inconforme frente a los despojos y relaciones de opresión que le depara Occidente. Ello se hizo particularmente evidente en el periodo del indigenismo ortodoxo con novelas como El mundo es ancho y ajeno (1941), del peruano Ciro Alegría; la ya mencionada José Tombé (1942), de Diego Castrillón Arboleda; y Tupaj Katari (1944), del boliviano Augusto Guzmán, todas ellas compuestas por el zurcido de las acciones de uno o varios indígenas levantados en armas o al menos objetivamente opuestos a las prácticas económicas y políticas de la sociedad mayoritaria. En contraste con ellas, la clásica Huasipungo (1934), de Jorge Icaza, llama la atención por “permitir” la parcial disolución de Andrés Chiliquinga — su personaje indio más definido — entre prolongados episodios en que toman parte diversos personajes del complejo marco social del pueblo de Tomachi y de la hacienda Cuchitambo. Sin embargo, Chiliquinga cede su lugar para que el foco de la narración sea ocupado por el personaje colectivo de la comunidad indígena expoliada, entidad cultural de la que ese presunto protagonista es nada más que su representación individual; algo muy diferente de lo que ocurre en La guerra perdida del indio Lorenzo, donde, si el general indio y su pueblo llegan a confundirse en una misma entidad, ello se da no tanto por transmutación simbólica cuanto por debilitamiento del motivo. En la novela de Baena el elemento indígena no domina la trama con su presencia, sino que apenas alterna 
con personajes, episodios y problemas ajenos a la lucha étnica, lo cual, entre otras cosas, denuncia una no correspondencia con la naturaleza epónima del título, realizada narrativamente de otra manera — con protagonismos casi excluyentes - por Castrillón Arboleda y Guzmán en sus respectivas novelas.

Por supuesto, no se trata apenas de una medición estadística de las apariciones del indio Lorenzo en la novela. Sobre todo, se trata de la densidad de su construcción como personaje étnico. Poco logra saberse de él más allá de conocer cómo son el rostro y los dedos del pie, además de los rasgos más generales de su historia personal: viene de las montañas de Coclé, fue educado por curas y representa a su pueblo en la lucha contra las vejaciones tributarias. No se tiene, sin embargo, ninguna noticia de su condición étnica específica más allá de la categoría genérica y mestiza de “cholo", la cual, por más que sea usada comúnmente para designar a los habitantes nativos de Coclé, estaría legítimamente ligada a las etnias ngöbe (actual) y cueva (extinta), ${ }^{5}$ y por ende a rasgos socioculturales particulares, de los que no se tiene ninguna noticia en la novela. En consecuencia, arrancado de su particularidad histórica, el reclamo por las exacciones tributarias y los robos de tierra se manifiesta, con evidente laconismo, como discurso genérico; como poco más que un requisito retórico para acercar la novela al canon indigenista, del cual sería un rasgo fundamental — de acuerdo con la clásica reflexión vertida por José Carlos Mariátegui en sus Siete ensayos de interpretación de la realidad peruana (1928) - el planteamiento del problema de la posesión y usufructo de la tierra ancestral. El narrador, por más que aluda al conocimiento que tendría Lorenzo de las particularidades de su pueblo, no logra vincular la figura del indio con ningún dato concreto y, por el contrario, llena su voz con ideas tópicas y difusas: "argumentaba con furia contenida pero con conocimiento de la historia de su gente, del país y de América entera" (66). Sobre la tierra suelta de esas palabras acaba emergiendo el discurso difuso del nacionalismo, como se deduce de una impresión postrera de Orduz a propósito de su amigo indio: "su idea de pueblo iba más allá de la que tenían en los días iniciales del levantamiento liberal, pues abarcaba la totalidad de

\footnotetext{
${ }^{5}$ Biblioteca Nacional de Panamá Ernesto J. Castillero R., “Los cholos y su componente genético”. Consultado el 13 de septiembre de 2016, http://binal.ac.pa/binal/index.php?option=com_content\&view=article\&id=82:los-cholos-de-cocle-y-sucomponente-genetico\&catid=82:ofrecemos.
} 
los habitantes del istmo sin distingos de raza" (216). Pero, como queda dicho, los primeros días de la inconformidad indígena se reducen a referencias igualmente vagas.

Con todo, la indefinición étnica en La guerra perdida del indio Lorenzo comporta un carácter ambiguo, porque, mientras se diluye la particularidad cultural de lo indígena, se dibuja con intensidad una presunta particularidad biológica que pondría al nativo muy cerca de la condición animal. De lo primero, además del comodín del discurso nacionalista atribuido a Lorenzo, puede sumarse una nueva prueba: la descripción fugaz y tópica de un pueblo indio que ha sido devastado por el ejército conservador; escribe Orduz:

[...] las tropas se ensañaron con los ancianos y con los niños que quedaba en el pueblo, pues los hombres adultos estaban todos desperdigados por el territorio del istmo en labores de siembra y cosecha. [...] Apenas oímos la noticia, un pequeño grupo de jinetes salimos a galope hacia el Cacao, a donde llegamos [...] para ver cómo echaban humo los rescoldos de los dieciocho ranchos de madera y paja del que había sido un pueblo campesino. (69)

Es claro que, al quedar diluida la concreción sociocultural de lo indio en la etiqueta de lo "campesino", basta aludir genéricamente a "siembra", "cosechas" y "ranchos de madera y paja" para cumplir con una estampa verosímil del escenario. Llama la atención que ese mismo episodio sea el que ofrece el pintoresco apunte — ya aludido — de la manera como están conformados los pies de Lorenzo, presa del desconcierto mientras recorre las ruinas dejadas por el ataque y quien, posiblemente a causa de su profundo desánimo, se antoja más bajo de estatura, "con sus pantalones arremangados hasta la mitad de las piernas y los pies descalzos, lleno de barro seco bajo las uñas y entre los dedos”. El narrador refiere que en esos pies, "característicamente campesinos", los dedos se disponen de modo extraño, "con apreciable distancia entre el dedo gordo y el pulgar", tal como son las extremidades de quienes suben a los árboles (70). Es ambigua —o, por mejor decir, asimétrica- esa contigüidad entre un pueblo que parece invisible en razón de su insulsa tipicidad y un individuo significativamente particularizado por rasgos acusados que, sin duda, lo acercan a la animalidad. Sin embargo, el aparente desajuste empieza a aclararse al considerar que esa condición peculiar de Lorenzo se extiende a los demás cholos, de quienes se cuenta que pueden imitar los sonidos de las criaturas selváticas con una fidelidad 
a todas luces sobrenatural, con "un cierto halo de esoterismo" (81). En ausencia de unos rasgos socioculturales diferenciadores, las cualidades animales de los indígenas emergen para expresar y definir la diferencia frente a sus opositores étnicos.

A propósito de la asunción del indio como un animal es necesario introducir una observación adicional. La fijación por la forma de los pies de Lorenzo y el interés de resaltar las dotes onomatopéyicas de los cholos corresponden enteramente al narrador: es desde la perspectiva de Orduz que esos rasgos se hacen llamativos. Sin embargo, no se trata de un punto de vista exclusivo, si se considera que es común incluso entre los miembros del bando enemigo. Como referimos más atrás, a propósito de los combates en el sitio de El Vigía, el mayor cuenta a su sobrino que seis cholos fueron tomados como prisioneros y que los soldados conservadores que los capturaron tenían para sí que se trataba de seres que "no alcanzaban la condición de humanos" (155). De modo que el mismo narrador participa en algún grado de la perspectiva mayoritaria y hegemónica que no ve en el indio un igual sino una criatura tan radicalmente diferente en su naturaleza que solo cabe clasificarla en otro orden.

Todo lo anterior deja entender que La guerra perdida del indio Lorenzo no puede concretar el tipo de reivindicación social de los nativos de Coclé que cabría esperar si se tratara, propiamente, de una novela indigenista. Ante la visión no totalmente solidaria del narrador, poco importa que aparezca el tema del reclamo tributario. ${ }^{6}$ Precisamente por no mediar otro tipo de compromiso político por parte de Orduz $-\mathrm{y}$ por ende otro tipo de conciencia y grado de interés por la coyuntura étnica - es que ese problema se plantea en la indefinición histórica. ${ }^{7}$ Sintomático de ese vacío es, por ejemplo, la noticia apenas vaga sobre la participación de la Iglesia en la sujeción de los habitantes de Coclé: el mayor Orduz cuenta que, para Lorenzo, la "caballerosidad" política estaba "aliada con el

\footnotetext{
${ }^{6}$ La queja por las exacciones tributarias es, dicho sea de paso, el asunto medular en el que quizá sea el primer relato indigenista escrito en Colombia, "María Ticince o los pescadores del Funza" (1860), de Eugenio Díaz Castro.

${ }^{7}$ A pesar de su abulia etnográfica, una novela como Los Clavijos(1943), del escritor colombiano Juan Álvarez Garzón, define con precisión documental el problema tributario que llevó a los indios de Túquerres a alzarse en 1800 contra el corregidor Francisco Clavijo y su hermano Atanasio, recaudador de impuestos; fechas, móviles, protagonistas y escenas del alzamiento son precisadas de modo tal que, incluso, podría "acusarse" a la novela de una suerte de desmedro literario en favor de un plegamiento mecánico a fuentes documentales que - como las partidas de defunción de los hermanos Clavijo - llegan a ser transcritas parcialmente (Álvarez Garzón 206).
} 
catolicismo" para afianzar el proyecto de "sometimiento y represión" que pesaba sobre los indios de Panamá (170). Pareciera que toda la particularidad histórica de la gesta reivindicadora de Lorenzo se redujera —más allá de las heterogéneas noticias sobre la guerra civil en el istmo - a la alusión al cacique Urracá que hay en la carta de Orduz; alusión que correspondería a poco más que un ornamento de discurso político muy común en la novela indigenista, de modo similar a como, en José Tombé, la narración compara al protagonista con Túpac Amaru (Castrillón Arboleda 143). ${ }^{8}$ Pero el discurso etnográfico de esta novela y su concentración narrativa en las vicisitudes de Tombé hacen que la referencia emblemática al revolucionario del siglo XVIII no parezca un indicio huero.

Casi sobra decir que las noticias difusas sobre las cosas indígenas no proceden, en ese estado precario, de la boca de Victoriano Lorenzo. La manera genérica, vaga y en algún gradoprejuiciada de dar cuenta del pasado y presente de los indios de Coclé corresponde a Vicente Orduz, mediador entre el líder nativo y Saúl Cantor, la persona interesada en conocer su gesta; el pasaje —invocado más arriba- en que el narrador refiere el “conocimiento" que tenía Lorenzo "de su gente, del país y de América entera" deja entender claramente quién posee la conciencia histórica y de quién procede el gesto sintético o, mejor, la incapacidad o el desinterés por abrir esa conciencia. Por lo demás,ya desde los primeros folios de la carta el mayor había dado a entender su interés apenas parcial por la figura de Lorenzo: tras recordarle a su sobrino que en un principio se sintió conmovido por sus preguntas a propósito del caudillo indio, había anotado que, una vez Cantor pareció olvidarse del tema, no iba a ser él — Orduz — "quien despertara de nuevo su curiosidad en ese sentido" (Baena, La guerra 13).

\section{Conclusión}

La conclusión de nuestra reflexión se impone por la fuerza de su obviedad: La guerra perdida del indio Lorenzo de Rafael Baena, a pesar de la adscripción discursiva que

\footnotetext{
8 De paso puede anotarse que esa sobreestimación del líder indígena tiene, en ambas novelas, un correspondiente estructural en la devaluación, por la barbarie, de uno de sus subalternos: los excesos cruentos en que cae Fidel Murillo, en la novela de Baena, son similares a los que protagoniza Eloy Cuají en José Tombé. Es plausible pensar que ambos personajes cumplen una función similar: recibir, por desplazamiento, la carga semántica negativa que le corresponde a la insurrección indígena como hecho violento, de modo que la figura central y emblemática del movimiento - tanto Lorenzo como Tombé— pueda conservar su "pureza".
} 
podría interpretarse en este título y de la inclusión, como línea argumental, de una historia de lucha indígena protagonizada por un caudillo nativo, no puede considerarse stricto sensu como una novela indigenista; por lo menos, no como una que pudiera matricularse en la corriente ortodoxa del indigenismo latinoamericano. Si en la novela consigue destacarse el personaje indio Victoriano Lorenzo, este protagonismo es apenas relativo y, sobre todo, se encuentra subordinado al desarrollo narrativo de otro objeto: la Guerra de los Mil Días, episodio que, en el caso de la narrativa histórica de Baena, es poco menos que un centro de gravedad. Dicho de otra manera: la actividad política y militar de Lorenzo alcanza a ser material novelesco por lo que tiene de hito histórico colombo-panameño y no — por lo menos no primordialmente-por lo que le corresponde en tanto manifestación americana indigenista.

Por lo anterior, La guerra perdida del indio Lorenzo tampoco puede considerarse como otra más entre las novelas históricas de tema indígena escritas en el país — como sí pueden serlo seis de las ocho obras mencionadas en los párrafos y notas de la introducción de este artículo- - Se percibe con claridad que, en la novela de Baena, la cuestión étnica está situada al margen del hito a propósito del cual se invoca y reescribe la documentación histórica existente: la guerra civil en Panamá en los primeros años del siglo XX. Es sobre todo para reconstruir esa situación bélica que parece ser usado el archivo histórico especializado, mientras que la cuestión indígena, más allá de algunas noticias y datos muy generales, se plasma más con arreglo a un discurso y unas imágenes tópicas sobre el indio americano: un discurso que lo construye como una víctima étnica apenas diferenciada, expoliada siempre de la misma manera, pero que también lo piensa como un ser singular por su cercanía a la condición animal. Es precisamente por estar situado por fuera de la condición humana que el indio estaría excluido de la experiencia histórica. ${ }^{9}$

Sin embargo, si no por su indigenismo ni por su aporte a la reconstrucción histórica de la cuestión indígena americana, en otro sentido La guerra perdida del indio Lorenzo sí puede pensarse inscrita en alguna corriente definida de la novela de tema indígena en

\footnotetext{
${ }^{9} \mathrm{Al}$ respecto conviene tener en cuenta la crítica formulada por Claude Lévi-Strauss contra el pensamiento de Jean-Paul Sartre, a propósito de que las concepciones occidentales de la historia tienden a identificarla con la noción de humanidad. Advierte el antropólogo que con esa equivalencia semántica se pretende "hacer, de la historicidad, el último refugio de un humanismo trascendental", pero que en realidad "la historia no está ligada al hombre, ni a ningún objeto particular" (Lévi-Strauss 380).
} 
Colombia: la corriente que desplaza su interés hacia entidades indígenas situadas más allá

de lo que - hechas todas las reservas del caso-podría concebirse como el ámbito nacional o local. En efecto, La guerra perdida del indio Lorenzo mira asuntos de la etnia ngöbe de Panamá de modo análogo a como Tríptico de la infamia lleva su mirada hasta los timucua de La Florida y La serpiente sin ojos arraiga en la selva venezolana; incluso habría que ligar, a esta serie, la propuesta de Finales para Aluna, cuyo argumento sitúa un fragmento de la cosmovisión amerindia en una ciudad alemana —Freiburg — donde ni siquiera hay migrantes indígenas. ¿Traduce ello una suerte de erudición o madurez etnológica de la literatura contemporánea? ¿O, por el contrario, tendrá que ver todo eso con una concepción generalizadora a la que, cada vez más, se le dificulta reconocer la particularidad de las culturas indígenas y no tiene otro recurso que pensarlas como una sola especie universal, representable en cualquiera de sus individuos? Al menos en el caso de La guerra perdida del indio Lorenzoes evidente que, al acomodar los indígenas ngöbe en el seno del vasto reino animal, apuesta por esa paradójica reducción por ampliación.

\section{Bibliografía}

Alegría, Ciro. El mundo es ancho y ajeno. Santiago: Ercilla, 1941.

Álvarez Garzón, Jaime. Los Clavijos. Pasto: Imprenta Departamental, 1964.

Anónima [atribuida a Félix Varela]. Jicoténcal. Houston: University of Houston, 1995.

Arango, Gustavo. Santa María del Diablo. Bogotá: Ediciones B, 2014.

Arango, Omar Adolfo. Príncipe de Chía: Enfrentamiento de dos mundos. Bogotá: Villegas, 2013.

Baena, Rafael. La bala vendida. Bogotá: Alfaguara, 2011.

Baena, Rafael. La guerra perdida del indio Lorenzo. Bogotá: Alfaguara, 2015.

Biblioteca Nacional de Panamá, Ernesto J. Castillero R. Los cholos y su componente genético.http://binal.ac.pa/binal/index.php?option=com_content\&view=article\&id= 82:1os-cholos-de-cocle-y-su-componente-genetico\&catid=82:ofrecemos

Buitrago, Jaime. La tierra es del indio. Bogotá: Minerva, 1955.

Castrillón Arboleda, Diego. José Tombé. Bogotá: Antena, 1942.

Díaz Castro, Eugenio. Novelas y cuadros de costumbres. Vol. 2. Bogotá: Procultura, 1985.

Escajadillo, Tomás G. La narrativa indigenista peruana. Lima: Amaru, 1994.

Friede, Juan. El indio en lucha por la tierra. Popayán: Unicauca, Comfacauca, 2010.

González Prada, Manuel. Horas de lucha. Lima: Universo, 1972.

Guzmán, Augusto. Tupaj Katari. México: F. C. E., 1944.

Icaza, Jorge. Huasipungo. Quito: Imprenta Nacional, 1934.

Lévi-Strauss, Claude. El pensamiento salvaje. México: F. C. E., 1994. 
Mariátegui, José Carlos. Siete ensayos de interpretación de la realidad peruana. Lima: Amauta, 1976.

Menton, Seymour. La Nueva Novela Histórica de la América Latina 1979-1992. México: F. C. E., 1993.

Montoya, Pablo. Tríptico de la infamia. Bogotá: Penguin Random House, 2014.

Ospina, William. La serpiente sin ojos. Bogotá: Random House Mondadori, 2012.

Pineda Botero, Álvaro. Teoría de la novela. Bogotá: Plaza \&Janés, 1987.

Pizarro Cortés, Carolina. “'¿Debería aceptar yo sin más, las paparruchas y embustes de vuestros cronistas?' (Las nuevas crónicas de Indias como reescrituras del descubrimiento y la conquista)". Alpha 31 (2010): 215-230.

Potdevin, Philip. Palabrero. Bogotá: Intermedio Editores, 2016.

Rodríguez-Luis, Julio. "Tercer avatar del indigenismo literario". Autour de l'Indigénisme. Une aproche littéraire de l'Amérique latine. Ed. Ernesto Mächler Tobar. París: Indigo-Université de Picardie Jules Verne, 2004. 125-140.

Sánchez, Luis Alberto. Proceso y contenido de la novela hispanoamericana. Madrid: Gredos, 1953.

Solano, Armando. Prosas. Bogotá: Minerva, 1935.

Vivas Hurtado, Selnich. Finales para Aluna. Bogotá: Ediciones B, Universidad de Antioquia, 2013.

Wade, Gerald E. y William H. Archer. “The Indianista Novel since 1889”. Hispania 23. 3 (1950): 215-216.

Zarza González, Ernesto. Moxa: El hijo del Sol. Bogotá: Ediciones B, 2015. 